\title{
A national census of those attending UK accident and emergency departments with asthma
}

\author{
M R Partridge, D Latouche, E Trako, J G B Thurston, on behalf of the UK National \\ Asthma Task Force†
}

\begin{abstract}
Objective-To obtain a representative national picture of the type of people with asthma attending accident and emergency (A\&E) departments in the UK, the reasons why they attend, and to determine the proportion admitted to hospital.
\end{abstract}

Design-A national census involving questionnaires.

Setting-100 A\&E departments throughout the UK.

Subjects-All those with asthma attending because of asthma during a one week period in September 1994.

Results-Details were obtained about 1292 attendances. About half of all attendances were by adults and half by children, and $\mathbf{8 7 . 8 \%}$ were previously diagnosed asthmatics; $\mathbf{1 8 . 8 \%}$ of adult attenders were unemployed. Perceived severity of asthma was the reason for attendance in $65.5 \%$, but $11.5 \%$ reported non-availability, or perceived non-availability, of the general practitioner (GP) as the reason for attending. One fifth of adults had been kept awake by their asthma for over three nights before attendance. 425 of the 1292 attenders (32.9\%) had been admitted to hospital in the previous 12 months and 316 (24.5\%) had attended the A\&E department in the previous three months. Only $\mathbf{2 4 . 6 \%}$ of attenders had had contact with their general practitioner in the previous 24 h. $61.6 \%$ of under-5 attenders $(n=341)$ were admitted to hospital; the figures for those aged 5-15 and 15+ years and above were $265(41.4 \%)$ and $665(38.7 \%)$.

Conclusions-Many people with asthma attend A\&E departments without first having seen their GP. In many adult cases the asthma, while severe, is not acute, but a high proportion of both adults and children are admitted to hospital. Many of these attendances and admissions are repeat attendances. To enhance the quality of care provided to those with asthma may require easier access to primary care, enhanced patient education, or enhanced health professional education. Further study is needed of a variety of potential interventions.

( $\mathcal{A}$ Accid Emerg Med 1997;14:16-20)

Keywords: asthma; A\&E attendance; hospital admission; quality of care

Nearly three million people in the United Kingdom have asthma. Approximately
100000 are admitted to hospital each year, the majority through accident and emergency (A\&E) departments. Another unknown number attend such departments but are not admitted, instead receiving treatment and being allowed home, possibly to be followed up by family doctor or hospital clinic. Many studies of those attending A\&E departments with asthma have been published ${ }^{1-7}$ and guidelines produced which suggest who should be seen in such departments and who should be admitted. ${ }^{89}$ However, we have remarkably little national data regarding the type of people with asthma attending $A \& E$ departments in the United Kingdom, but there is evidence from this country and overseas that the numbers are increasing. ${ }^{10-12}$

This observational study was designed to provide a national picture of the type of people attending $A \& E$ departments in the United Kingdom because of asthma. The aim was to obtain demographic data, information about prior care, and details of perceived severity and reasons for attendance and disposal.

\section{Methods}

Every $A \& E$ department listed in the British Association for Accident and Emergency Medicine 1993 handbook (nearly 500 departments), irrespective of size, was sent a letter outlining the aims of the study and inviting participation. Replies were received from 226 departments in a wide geographical area with a spread of teaching and non-teaching hospitals in urban and semi-urban areas, with only 24 declining to participate. All responders from departments listed as having a full time accident and emergency consultant who were also reported as having more than 30000 new patient attendances per annum were then recruited to the survey (111 departments). Each was sent advance notices for staff to publicise the week-long survey, with triage nurses and $A \& E$ medical staff being asked to complete a one side A4 census form (see Appendix) containing 20 pieces of information on all persons attending their department with asthma between 9 am on Wednesday, 21 September 1994 and 9 am on Wednesday 28 September 1994. The A\&E consultant was asked to prepare staff

†The UK National Asthma Task Force is coordinated by the National Asthma Campaign and comprises representatives from the National Asthma Campaign, British Thoracic Society, British Paediatric Association, British Paediatric Respiratory Group, The Royal College of Physicians, the Department of Health, the Committee on Safety of Medicines and the GPs in Asthma Group. 
Table 1 Ages of those attending $(n=1292)$

\begin{tabular}{lll}
\hline Age range & No of attendances & Percentage of total population \\
\hline Under 5 & 341 & $26.4 \%$ \\
Under 15 & 606 & $46.9 \%$ \\
15 and over & 665 & $51.5 \%$ \\
65 and over & 84 & $6.5 \%$ \\
\hline
\end{tabular}

21 forms had no stated age and on 14 forms the stated age was zero, presumably implying attender was an infant.

for the census and was provided with instructions suitable for notice boards, and handouts and copies of the census form. One week before the survey, each department was sent 30 census forms. A phone and fax number were provided so that departments could obtain more information or seek any clarification necessary. On the first day of the census each department received a further reminder of the key points about the census. Staff were asked to ensure that a form was completed at the time of attendance of each person with a primary presenting symptom of asthma attending during the relevant time period. "Asthma" was not defined and those. seeking clarification were advised that their usual use of the term should be adopted but that we were seeking information about people with reversible airway narrowing. Each A\&E consultant was asked to ensure prompt return of the census forms at the end of the week and to use whichever methods were available to check for completeness of the attendances recorded-either by manual search of attendance registers or by computer checks. Forms returned to the coordinating centre were then entered onto a computer database.

\section{Results}

One hundred of the $111 \mathrm{~A} \& \mathrm{E}$ departments recruited to the census returned census forms relating to 1292 attendances of people with asthma during the census week. Two hospitals returned forms saying that they had had no attendance of people with asthma during the survey week, and nine hospitals which had agreed to take part did not do so. Five hundred and sixty seven attendances were by females $(44.9 \%), 695$ by males $(55.1 \%)$, and in 30 cases gender was missing from the census forms.

Table 1 shows the age range of those attending and it can be seen that roughly half of all attendances were by adults and half by children. Of the adults whose forms included information about occupation (657), 268 (40.8\%) were employed, 112 ( $17.7 \%)$ unemployed, 111 (16.9\%) housewives, 105 (16.0\%) students, and $61(9.3 \%)$ retired. If the retired adults are excluded, then $112(18.8 \%)$ of adult attenders were unemployed at a time when the national average for unemployment was $8.3 \%$.

The majority of those attending [1134 $(87.8 \%)$ ] already knew that they had asthma but $112(8.7 \%)$ were new asthmatics. (Information was missing on 46 forms.) Most attendances (500) occurred during the evening (40.1\%), with 417 people attending between 9 am and $5 \mathrm{pm}(33.7 \%)$, and 322 between midnight and 9 am (26\%). Time of attendance was
Table 2 Admission rates for children of school age, preschool age, and adults

\begin{tabular}{llll}
\hline Age range & No admitted & No attending & Percentage admitted \\
\hline Under 5 & 210 & 341 & $61.6 \%$ \\
$5-15$ & 109 & 265 & $41.4 \%$ \\
15 and above & 257 & 665 & $38.7 \%$ \\
\hline
\end{tabular}

not stated on 36 forms. There was no difference in attendance times according to age.

There were 341 attendances by those aged under 5 years of age, and $210(61.6 \%)$ of these were admitted to hospital. Admission rates for other ages are shown in table 2 . Of those attending, $1211(97.7 \%)$ were registered with a general practitioner (GP), 29 were not, and 52 forms did not contain this information.

REASONS FOR ATTENDING A\&E

When asked the reasons for attending, 728 $(65.5 \%)$ declared severity as the reason. Sixty $(5.4 \%)$ stated that they had tried their GP, who was unavailable, and $68(6.1 \%)$ stated they thought the GP would be unavailable but had not attempted contact. Details about patients' prior contact with their GP are shown in table 3. Forty two $(3.8 \%)$ were visitors to the area and $92(8.3 \%)$ reported they had run out of inhalers as the reason for attending.

\section{ACUTENESS OF ATTACK AND SEVERITY}

Perceived severity of asthma was the reason for two thirds of patients attending the emergency department, and among adults the average number of nights during which the patient had been kept awake by asthma before attendance was 3.1. One fifth of those attending (20.8\%) reported having been kept awake for more than three nights before attending. Of the adults, $37.7 \%$ reported having their own peak flow meter.

\section{PREVIOUS ADMISSIONS/ATTENDANCES}

Of the 1292 attenders, 425 (32.9\%) had been admitted to hospital in the previous 12 months and $316(24.5 \%)$ had attended $A \& E$ departments in the previous three months.

\section{FOLLOW UP}

Five hundred and seventy six attenders were admitted to hospital from the A\&E departments and census forms were complete for 562 of the others who were sent home. Of these, $439(78.1 \%)$ were said to have been referred back to their GP, and $123(21.9 \%)$ were referred to a hospital clinic.

\section{Discussion}

This study gives insight into the types of people attending A\&E departments throughout the United Kingdom because of asthma. The results reflect the high prevalence of asthma among young children and show that a high proportion of both children and adults attending $A \& E$ departments with asthma are eventually admitted. The severity of their condition 
Table 3 Contact with general practitioners

\begin{tabular}{lll}
\hline & $n$ & $\%$ \\
\hline Within the previous 24 hours & 297 & 24.6 \\
Between 1 and 7 days before presentation & 138 & 11.4 \\
Between 7 and 28 days before attendance & 212 & 17.5 \\
More than 1 month previously & 363 & 30 \\
\hline
\end{tabular}

was reported by the patients to be the main reason for their attendance. Prodromal sleep disturbance, previous attendance, and the high admission rate would certainly appear to confirm that the condition of many was severe. However, clearly not all presenting asthma is acute, for over one fifth of adults had been waking at night for at least three nights before attending, and time would therefore have been available for well educated patients to have adjusted treatment to abort the attack. This is in keeping with previous reports from single institutions. ${ }^{13}$ While $38 \%$ of adults had peak flow meters, we do not know what proportion used those as part of a self management plan. Several recent studies have confirmed the value of such self management plans in reducing morbidity and hospital attendances, ${ }^{14-18}$ and our report would suggest that there is considerable scope for further education of patients, especially since a quarter of those attending had also attended in the previous three months. This education should be done in an anticipatory manner within the context of a partnership between patient (parent) and primary care health professional, but it is possible that more could be done within the $A \& E$ department. While an exacerbation of asthma may not be the ideal time during which to educate a patient, it may be the only opportunity available with some patients. As a minimum, staff should reiterate the importance of the taking of regular preventative treatment and give some advice about signs which suggest worsening of asthma and what to do in those circumstances (for example, increase preventative medication at the first sign of deterioration). This verbal advice should preferably be reinforced by the provision of written information. ${ }^{1920}$ Time spent receiving nebulised bronchodilators could perhaps be spent watching videos about the condition, and these have been shown to be popular with patients, ${ }^{21}$ suitable for those with poor literacy skills, and excellent for teaching practical skills (such as inhaler techniques). ${ }^{22}$ They are available in several languages for those from the IndoPakistan subcontinent (National Asthma Campaign, Providence House, Providence Place, London, N1 0NT). Eight per cent of patients attended because they had run out of inhalers but it is not known whether this was the sole cause or whether severity of asthma leading to unexpected increased use of the inhaler was the main problem. Perhaps more patients should be advised that emergency inhaler replacements can be obtained from pharmacists without prescription.

Other published studies have suggested that many exacerbations of asthma are treated, and successfully treated, by general practitioners. $^{2324}$ We have no way of knowing what proportion that comprises, but the current study suggests that, of those attending an $A \& E$ department with asthma, only a minority had consulted their primary care physician recently. This may be because they have been previously instructed to go straight to the $A \& E$ department, or because of patient or parent perception of severity, or because of a desire "not to trouble the doctor". All of these "true" reasons for attendances in $\mathrm{A} \& \mathrm{E}$ require further study. Having attended, $62 \%$ of preschool children and well over one third of older children and adults are admitted. Whether all such admissions are essential cannot be answered by the current study, but other studies have suggested that certain interventions can safely reduce the admission rate. For example, the use of peak flow guidelines in those old enough to use a meter can lead to an increase in the number of children safely sent home. ${ }^{25}$ Most attenders will be seen by relatively inexperienced staff who correctly "play safe" in cases of doubt and admit for observation. However, in view of the large number who had not seen their general practitioner before attendance, some departments with primary care physicians in attendance may triage some patients with asthma to that area of the A\&E department. Others have shown that use of more experienced staff or greater training of junior staff in the management of asthma can lead to reduced admissions and the safe discharge of many. $^{27-30}$

This study showed that of those discharged, the majority were referred back to their general practitioner with a letter, and one fifth of attenders were referred to a hospital outpatient clinic. Leaving the patients themselves to make contact with their general practitioner may not be ideal, for attendance is a sign of poorly controlled asthma and proper review arrangements are essential. Perhaps this could be done more effectively by fax, and in some districts this has been done by the appointment of an emergency services practice manager ${ }^{31}$ or by the use of paediatric liaison nurses; but perhaps we should be more innovative and there seems to be scope for trial of alternative methods of follow up, such as by telephone. ${ }^{32}$

In conclusion, the information collected by this census shows that many people with asthma attend $A \& E$ departments without first seeing their GP. In many adult cases symptoms had been present for some time and better education and advice regarding self management might have enabled the patients to regain control of their asthma without having to attend the A\&E department. The high reattendance and readmission rates may reflect severity of disease, but they also raise the question of whether-in addition to patient education-better education of health professionals and the use of guidelines might not safely reduce the numbers of people with this common condition attending A\&E departments and being admitted from there. The whole question of the management of those with asthma attending $\mathrm{A} \& \mathrm{E}$ departments should be reviewed in each district by local asthma task forces. 


\section{Key messages}

- Once in an A\&E department many children and many adults attending with asthma are admitted.

- Asthma in adults, while often severe, is not always acute.

- Many attenders have not previously seen their GP but have previous experience of hospital admission or $\mathrm{A} \& \mathrm{E}$ department attendance.

We are extremely grateful to colleagues in accident and emergency departments throughout the United Kingdom who so willingly completed census forms in addition to their othe duties. The very high rate of cooperation and compliance with the study is a tribute to the desire of accident and emergency departments to improve the quality of health care and to raise standards of audit and scientific study.

Members of the Organisation of Care Working Party of the National Asthma Task Force include Dr Elizabeth Hills, Dr Fiona Moss, Mrs Greta Barnes, Dr Mark Levy, Professor Sean Hilton, Dr Mike Pearson, Dr David Heaf, Dr Mac Cochrane, and Dr M R Partridge (Chairman), and we acknowledge thei considerable help both with the design of the study and with advice with the preparation of this report. Dr J G B Thurston was instrumental in gaining the considerable cooperation of the British Association of Accident and Emergency Medicine.

This study was funded by the Department of Health

\section{Appendix}

An example of the census form used in the study.

UK ASTHMA CENSUS WEEK

ONE FORM TO BE COMPLETED FOR EACH PATIENT ATTENDING ACCIDENT AND EMERGENCY DEPARTMENT WITH THE PRIMARY PRESENTING SYMPTOM OF ASTHMA

NB: It is essential that this form be completed at the time and not in retrospect

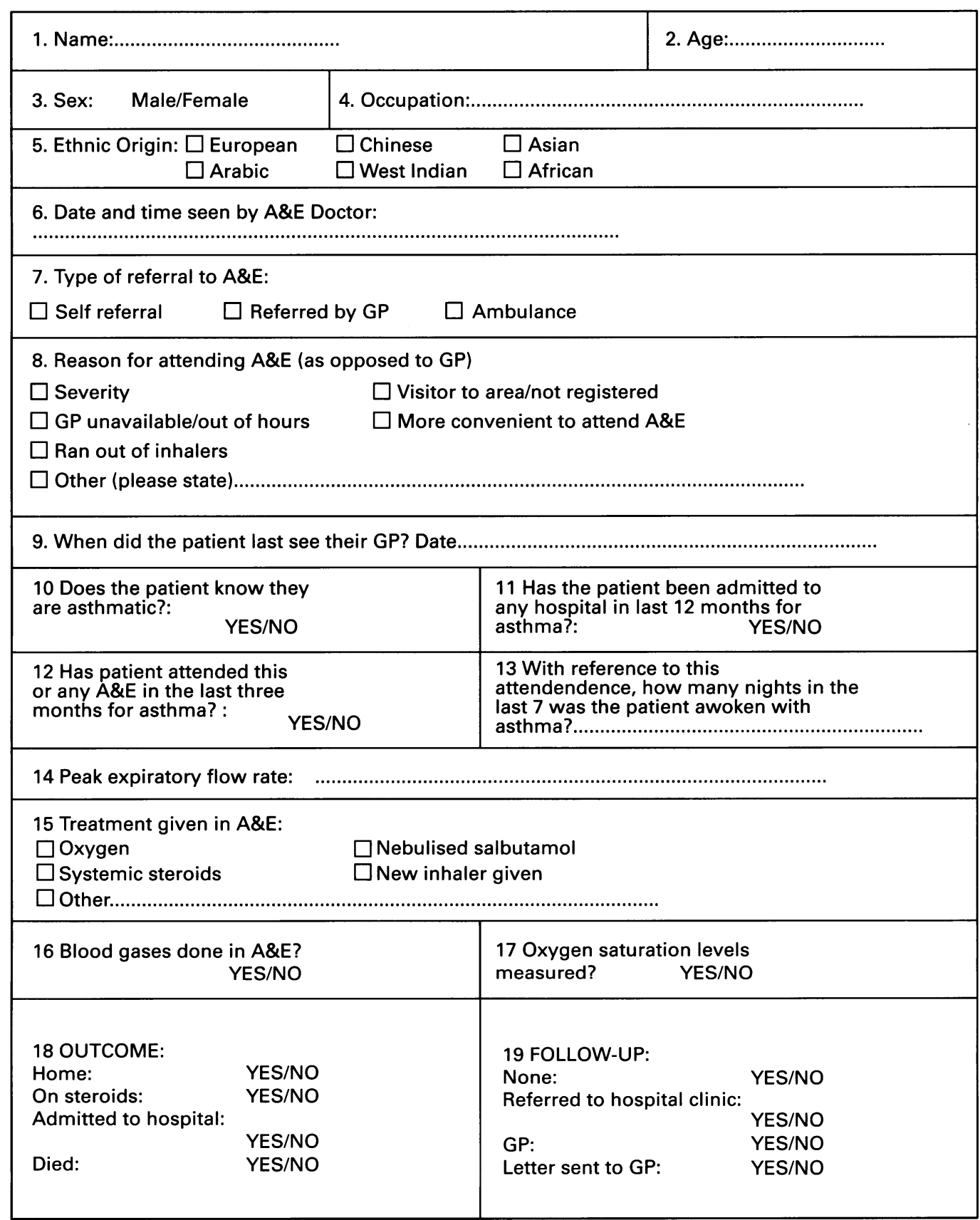


1 O'Halloran SM, Heaf DP. Accident and emergency department attendances by asthmatic children. Thorax ment attendance

2 Kwong T, Town I, Holst PE, Beasley R. A study of management of asthma in a hospital emergency department. NZ ment of asthma in a hos.

3 Dales RE, Schweitzer I, Kerr P, Gougeon L, Rivington R Draper J. Risk factors for recurrent emergency department visits for asthma. Thorax 1995;50:520-4

4 Rossi OVJ, Kinnula VL, Huhti E. Emergency room visits fo acute attacks of asthma: characterisation of patients and visits. Respiration 1991;58:21-5.

5 Chidley KE, Wood-Baker R, Town GI, Sleet RA, Holgate ST. Reassessment of asthma management in an acciden and emergency department. Resp Med 1991;85:373-7.

6 Coonar AS, Nayeem N, Bowell CP, Shires SR. Adult asthma assessment in an accident and emergency department. J R Soc Med 1994;87:330.

7 Newcomb RLI, Akhter J. Outcomes of emergency room visits for asthma. J Allergy Clin Immunol 1986;77:309-14.

8 National Heart, Lung \& Blood Institute, National Institutes of Health. International consensus report on diagnosis and management of asthma. Publ No 92-3091, 1992.

9 British Thoracic Society, British Paediatric Association, Royal College of Physicians of London, The Kings Fund Royal College of Physicians of London, The Kings Fund Centre, The National Asthma Campaign, et al. Guidelines on the management of asthma. Thorax 1993;8

10 Anderson HR. Increase in hospital admissions 1970-1985. Thorax 1989;44:614-9.

11 Kun HY, Oates RK, Mellis CM. Hospital admissions and attendances for asthma - a true increase? Med J Aust 1993; 159:312-3.

12 Garrett JE, Mulder J, Veale A. Trends in the use of an urban accident and emergency department by asthmatics. NZ Med J 1988;101:253-5.

13 Blainey AD, Beale A, Lomas D, Partridge MR. The cost of acute asthma-how much is preventable? Health Trends 1991;22:151-3.

14 Souza WD, Crane J, Burgess C, Te Karv H, Fox C, Harper $M$, et al. Community-based asthma care: trial of a "credit card" asthma self management plan. Eur Respir J 1994;7:1260-5.

15 Wilson SR, Scamagas P, German DF, Hughes GW, Lulla S, Coss $S$, et al. A controlled trial of two forms of self management education for adults with asthma. Am J Med 1993;94:564-76.

16 Yoon R, McKenzie DK, Bauman A, Miles DA. Controlled trials evaluation of an asthma education programme for adults. Thorax 1993;48:1110-6.

17 Bailey WC, Richards JM, Brooks M, Soong S-J, Windso RA, Manzella BA. A randomized trial to improve self manRA, Manzella BA. A randomized trial to improve self management practices

18 Ignacio-Garcia J, Gonzales-Santos P. Asthma self management education program by home monitoring of peak expiratory flow. Am J Respir Crit Care Med 1995;151:353-9.

19 Raynor DK, Booth TG, Blenkinsopp A. Effect of computer generated reminder charts on patients compliance with drug regimens. BMJ 1993;306:1158-61.

20 Pedersen S. Ensuring compliance in children. Eur Resp J 1992;5:143-5.

21 Partridge MR. Asthma education; more reading or more viewing? J R Soc Med 1986;79:326-8.

22 Mulloy EMT, Albazark MK, Warley ARH, Harvey JE. Video education for patients who use inhalers. Thorax 1987;42:719-20.

23 Neville RG, Clark RA, Hoskins G, Smith B. First national audit of acute asthma attacks in general practice 1991audit of acute asthma attacks
1992. BMJ 1993;306:559-62.

24 Neville RG Clark RC, Hoskins SG, Smith B (for the General Practitioners in Asthma Group). GPIAG National eral Practitioners in Asthma Group)

25 Taylor $M R$ Asthm admissions and discharges. Arch Dis Child 1994;70:432-4 26 Dale J, Green J, Reid F, Glucksman E, Higgs R. Primary care in the accident and emergency department II comparison of general practitioners and hospital doctors. BMJ 1995;311:427-30.

27 Connett GJ, Warde C, Wooler E, Lenney W. Audit strategie to reduce hospital admissions for acute asthma. Arch Dis Child 1993;69:202-5

28 Hendricson WD, Wood PR, Hidalgo HA, Krumer ME, Parcel GS, Ramirex AG. Implementation of a physician education intervention: the childhood asthma project. Arch Pediatr Adolesc Med 1994;48:595-601.

29 Town $L$ Kwong $T$, Holst $P$, Beasley $R$. Use of a management plan for treating asthma in an emergency management plan for treating asthm

30 Duke T, Kellerman A, Ellis R, Arheart K, Self T. Asthma in the emergency department: impact of a protocol on optimising therapy. Am J Emerg Med 1991;9:432-5.

31 Hadfield JM, Yates DW, Berry A. The emergency department and the community: a model for improved cooperation. J R Soc Med 1994;87:663-5.

32 Rao JN. Follow up by telephone. BMJ 1994;309:1527-8.

\section{Referees for the Fournal of Accident $\mathcal{E}$ Emergency Medicine}

All papers submitted for publication in the Journal of Accident \& Emergency Medicine undergo peer review. As a result of the continuing rise in the number of papers received the Journal seeks additional referees.

This is an interesting and stimulating activity. The Editorial Office ensures that the workload for referees is not onerous and guidelines are provided to allow a structured critique of each paper. Referees are expected to return comments within three weeks of receipt of the manuscript.

Please contact the Editor, Journal of Accident \& Emergency Medicine at BMA House, Tavistock Square, London WC1H 9JR, telephone 0171-383-6795, fax. 0171-383-6668, stating your present appointment and any areas of special expertise. Reviewers are particularly welcome from other specialties with an interest in Emergency Medicine and from outside the U.K. 